\title{
Down-regulation of Mcl-1 with antisense technology alters the effect of various cytotoxic agents used in treatment of squamous cell carcinoma of the head and neck
}

\author{
CHRISTIANE SKODA ${ }^{1}$, BOBAN M. EROVIC ${ }^{5}$, VOLKER WACHEK ${ }^{2}$, \\ LAURENZ VORMITTAG ${ }^{3}$, FRITZ WRBA $^{4}$, HELGA MARTINEK ${ }^{5}$, GREGOR HEIDUSCHKA ${ }^{5}$, \\ PHILIPP KLOIMSTEIN $^{5}$, EDGAR SELZER $^{1}$ and DIETMAR THURNHER ${ }^{5}$
}

\begin{abstract}
Departments of ${ }^{1}$ Radiotherapy and Radiobiology, ${ }^{2}$ Clinical Pharmacology, ${ }^{3}$ Internal Medicine, Division of Oncology,
${ }^{4}$ Clinical Pathology and ${ }^{5}$ Otorhinolaryngology, Head and Neck Surgery, Medical University of Vienna, Austria
\end{abstract}

Received December 20, 2007; Accepted February 8, 2008

\begin{abstract}
Antisense oligonucleotides have recently been identified as new anticancer agents. Since human head and neck cancer cells highly express the antiapoptotic protein myeloid cell leukemia-1 (Mcl-1), the aim of this study was to explore the efficacy of the Mcl-1 suppression in combination with various cytotoxic agents in the head and neck cancer cell line SCC9. After oligonucleotide transfection and/or treatment with cisplatin, 5-fluorouracil (5-FU), gemcitabine, paclitaxel or cetuximab, proliferation assays were performed to determine cell viability. The expression patterns of Mcl-1, Bax and Bak were assessed by Western blot analysis and the apoptotic cells were determined by immunohistochemistry using the M30 antibody. A combined Mcl-1 antisense oligonucleotide treatment with paclitaxel, cetuximab and gemcitabine led to a significant reduction in the viable cells. However, the combination with cisplatin and 5-FU showed only moderate synergistic cytotoxic effects. According to the cytotoxic data, distinct apoptosis rates were observed after the combined treatment with the different substances. Western blot analysis also showed a significant suppression of the Mcl-1 synthesis. Our data show that the Mcl-1 antisense oligonucleotide in combination with certain cytotoxic agents has the potential to significantly decrease cell viability in vitro.
\end{abstract}

\section{Introduction}

Head and neck cancer is the sixth most common neoplasm in the world today (1). More than 500,000 cases are diagnosed worldwide each year, most of which are locally advanced at

Correspondence to: Dr Dietmar Thurnher, Department of Otorhinolaryngology, Head and Neck Surgery, Medical University of Vienna, Währinger Gürtel 18-20, A-1090 Vienna, Austria E-mail: dietmar.thurnher@meduniwien.ac.at

Key words: myeloid cell leukemia-1, antisense, apoptosis, head and neck squamous cell carcinoma, cancer presentation, meaning either stage III or IV. The treatment of head and neck cancer is generally based on surgery and radiotherapy, whereas a combination of the former with chemotherapy is reserved for advanced cancers or the palliative setting (2). The DNA-damaging drug cisplatin is the most commonly used single agent with reported response rates of $14-41 \%(3,4)$ for all tumor stages and is frequently used in combination with other agents, particularly 5-FU (2) or the taxanes (3). Despite the use of aggressive therapy for the primary disease, locoregional recurrences are observed in $>60 \%$ of the treated patients and metastatic disease occurs with a rate of up to $20-25 \%$ (5). Although a number of patients with recurrent and/or metastatic disease respond to chemotherapeutic agents, the prognosis remains poor once tumor relapse occurs (5). Therefore, the identification of new anticancer agents is required to improve the generally poor prognosis of patients with advanced head and neck cancer. One such class of new antitumor agents is the antisense oligonucleotide therapy (6).

Antisense oligonucleotides are chemically modified stretches of single-stranded DNA. Once they enter a target cell, they bind to their complementary mRNA and inhibit the expression of the corresponding disease-relevant protein (7). Antisense oligonucleotides have shown promising results as agents for the specific manipulation of gene expression and have been used to inhibit gene expression in vitro and in vivo $(8,9)$. Specifically, the antisense therapy has been used to inhibit members of the Bcl-2 protein family, which are involved in the regulation of apoptosis (6).

The aim of the present study was to examine whether the Mcl-1 (myeloid cell leukemia-1) protein is an attractive target for the antisense treatment of head and neck cancer. Mcl-1 is expressed in up to $90 \%$ of locally advanced tumors of the head and neck region whereas the namesake of the family, the Bcl-2 protein, is only expressed in $15 \%$ (10).

The Mcl-1 protein is an antiapoptotic protein of the Bcl-2 protein family (7). Mcl-1 is expressed in a variety of tissues and neoplastic cells and plays an important role in the development of several malignancies (7). Mcl-1 has also been shown to be involved in the regulation of cell cycle progression (11). 
In the present study, we used the Mcl-1 antisense oligonucleotide to down-regulate the Mcl-1 protein expression in human head and neck cancer cells. The main aim of the study was to investigate whether the decreased Mcl-1 protein level had a synergistic cytotoxic effect with various clinically used agents, including cisplatin, 5-FU, gemcitabine and paclitaxel and specifically the monoclonal antibody cetuximab in vitro.

\section{Materials and methods}

Cell line and cultures. The tumor cell line SCC9, a head and neck squamous cell carcinoma (HNSCC) cell line of the tongue, was obtained from the American Type Culture Collection (Rockville, MD, USA). Cells were cultured in RPMI medium containing $10 \%$ FCS, $100 \mathrm{U} / \mathrm{ml}$ penicillin and $100 \mu \mathrm{g} / \mathrm{ml}$ streptomycin (all reagents from Life Technologies Ltd., Paisley, Scotland) and grown at a humidified atmosphere of $5 \% \mathrm{CO}_{2}$.

Oligonucleotides and transfection. 2'-O-Methoxyethyl/2'deoxynucleotide chimeric phosphorothioate antisense oligonucleotides were obtained from ISIS Pharmaceuticals (Carlsbad, CA, USA). The Mcl-1 antisense oligonucleotide sequence was 5'-TTGGCTTTGTGTCCTTGGCG-3'. The universal control oligonucleotide used in this study was synthesized as a mixture of $\mathrm{A}, \mathrm{G}, \mathrm{T}$ and $\mathrm{C}$ bases so that the resulting preparation contained an equimolar mixture of all possible oligonucleotide sequences. The oligonucleotide backbone chemistry of the universal control was identical to that of antisense. For transfection, $7 \times 10^{5}$ cells were seeded in 6-cm tissue-culture dishes $24 \mathrm{~h}$ prior to the oligonucleotide treatment. Oligonucleotides were complexed with TransFectin lipid reagent (Bio-Rad Laboratories, CA, USA) in serum-free medium as described by the manufacturer. Subsequently, the cells were incubated for $24 \mathrm{~h}$ with $35-150 \mathrm{nM}$ complexed oligonucleotides $(1.5 \mathrm{mg} / \mathrm{ml}$ TransFectin $)$ in serum-containing medium.

Study drugs. Cetuximab (Erbitux), a chimeric immunoglobulin $\mathrm{G} 1$ ( $\left.\mathrm{IgG}_{1}\right)$ monoclonal antibody, was received from Merck (Darmstadt, Germany). The other reagents (cisplatin, 5-fluorouracil, gemcitabine and paclitaxel) were ready-to-use infusions, which were dissolved in PBS and stored at room temperature.

Quantification of the cell number. For the cell proliferation experiments, cells were seeded in 96-well plates (3000 cells/ well) $24 \mathrm{~h}$ before the oligonucleotide treatment and then incubated with $35 \mathrm{nM}$ antisense oligonucleotide in the presence of TransFectin, as described above. After an incubation period of $24 \mathrm{~h}$, the cells were treated with various concentrations of cisplatin $(0-3 \mu \mathrm{g} / \mathrm{ml}), 5-\mathrm{FU}(0-12 \mu \mathrm{g} / \mathrm{ml})$, gemcitabine $(0-15 \mathrm{ng} / \mathrm{ml})$, paclitaxel $(0-5 \mathrm{ng} / \mathrm{ml})$ and cetuximab $(0-150 \mathrm{ng} / \mathrm{ml})$. Finally, the determination of cell viability was performed by using a Cell counting kit-8 (Dojindo Laboratories, Kumamoto, Japan) according to the manufacturer's instructions. Absorbance was determined for each well at $450 \mathrm{~nm}$ using an Anthos htII microplate reader (Anthos Labtec instruments, Salzburg, Austria). The controls were handled during the experiments exactly as the treated cells.
Western blot analysis. Western blot analysis was used to determine Mcl-1 expression $24 \mathrm{~h}$ after the oligonucleotide treatment. Cell extracts were prepared in lysis buffer, consisting of $1 \%$ Nonidet P40, $0.1 \%$ SDS, $150 \mathrm{mM} \mathrm{NaCl}, 50 \mathrm{mM}$ tris/pH 7.4, $10 \mathrm{mM}$ EDTA, $10 \mathrm{mM}$ p-nitrophenolphosphate, $250 \mathrm{U} / 1$ aprotinin, $40 \mu \mathrm{g} / \mathrm{ml}$ leupeptin, $1 \mathrm{mM}$ PMSF, $1 \mathrm{mM}$ sodium orthovanadate, $10 \mathrm{mM}$ sodium fluoride and $40 \mathrm{mM}$ $\beta$-glycerophosphate. The cell lysates were centrifuged at $14,000 \mathrm{rpm}$ for $20 \mathrm{~min}$ at $4^{\circ} \mathrm{C}$. The amount of soluble protein was quantified by using a micro BCA from Pierce (Rockford, IL, USA). Total protein lysates (20 $\mu \mathrm{g} /$ lane) were separated by a $10 \% \mathrm{SDS} / \mathrm{PAGE}$ and blotted onto nitrocellulose membranes (Schleicher \& Schuell, Dassel, Germany). The membranes were incubated with anti-Mcl-1 (Neomarkers, Fremont, CA, USA), anti-Bax and anti-Bak antibodies (all from Santa Cruz Biotechnology Inc., Santa Cruz, USA). Bound antigen was visualized with the ECL Western blotting analysis system (Amersham Life Sciences, Buckinghamshire, UK).

Immunohistochemistry. For the detection of apoptosis we used a mouse monoclonal antibody against the M30 neo-epitope. SCC9 cells were grown under standard conditions on glass slides for seven days before the oligonucleotide treatment, to gain fully overgrown slides. The slides were washed twice with cold PBS, fixed and dehydrated using decreasing ethanol concentrations. The slides were subjected to antigen retrieval in a microwave oven for $2 \times 5 \mathrm{~min}(600 \mathrm{~W})$ using $1 \mathrm{mM}$ EDTA-buffer ( $\mathrm{pH} 8.0$ ). To reduce the background signals, samples were treated with 5\% BSA (Sigma-Aldrich, Vienna, Austria)/tris-buffered saline (TBS) for $30 \mathrm{~min}$. After the blocking step, the slides were incubated with monoclonal mouse antibody CytoDeath M30 (1:50, Roche, Mannheim, Germany) overnight at room temperature. The following day, all of the slides were washed three times for 5 min with TBS. Samples were incubated with biotinylated mouse antibody (1:100, Vector Laboratories, Burlingame, CA, USA) for $1 \mathrm{~h}$, washed and incubated with alkaline phosphatase-conjugated streptavidine-AP/10\% human serum (1:100, Dako, Denmark) for $1 \mathrm{~h}$ at room temperature. Visualization was achieved with fast red (Sigma, MO, USA) and counterstaining with haemalaun. The slides were dehydrated and embedded in Kaiser-Gelatine (Merck).

Statistical analysis. Statistical analysis was performed using GraphPad 4.0 software from PRISM (GraphPad Software Inc., CA, USA). A comparison of the means was carried out by the Student's unpaired t-test and a p-value of $<0.05$ was considered statistically significant. Synergistic effects were quantified using the formula described by Aapro et al (12). The error bars represent the standard errors of the means of the experiments which were performed three times.

\section{Results}

Expression of Bcl-2 family members Mcl-1, Bax and Bak after treatment with the Mcl-1 antisense oligonucleotide and study drugs. As demonstrated by Western blot analysis, the HNSCC cell line SCC9 was found to express the antiapoptotic protein Mcl-1 and the proapoptotic proteins Bax and Bak, all 


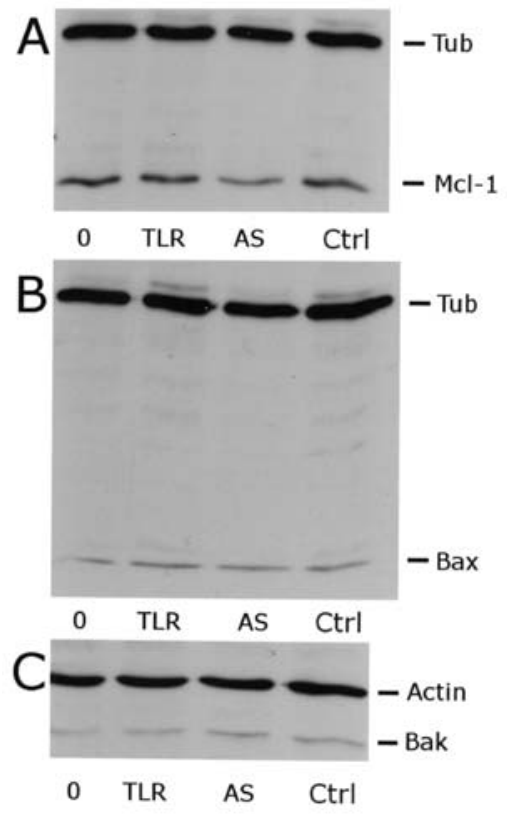

Figure 1. The effects of the Mcl-1 antisense oligonucleotide on (A) Mcl-1, (B) Bax and (C) Bak protein expression levels. A western blot analysis of SCC 9 cells $24 \mathrm{~h}$ after treatment with $50 \mathrm{nM}$ oligonucleotide in the presence of TransFectin. Lane 1, control (0); lane 2, TransFectin control (TLR); lane 3, Mcl-1 antisense oligonucleotide (AS) and lane 4, universal control oligonucleotide (Ctrl).

members of the Bcl-2 protein family (Fig. 1). By using the Mcl-1 antisense oligonucleotide at nanomolar concentrations, we observed a considerable reduction in the Mcl-1 protein levels in vitro. A comparison of the Mcl-1 synthesis to the control showed that the antisense oligonucleotide treatment caused a significant reduction of the Mcl-1 protein levels versus cells treated with the universal control oligonucleotide.

The treatment of SCC9 cells with $50 \mathrm{nM}$ antisense oligonucleotide reduced the Mcl-1 levels by $\sim 50 \%$ after an incubation period of $24 \mathrm{~h}$. In contrast, Western blot analysis of SCC9 cells treated with the same concentration of the universal control oligonucleotide did not demonstrate any significant alteration in the expression of Mcl-1 (Fig. 1A). Regarding the proapoptotic proteins, treatment of the cells with the Mcl-1 antisense oligonucleotide did not change Bax and Bak protein levels in our investigated cell line (Fig. 1B and $\mathrm{C})$.

Western blot analysis of SCC9 cells treated with $35 \mathrm{nM}$ Mcl-1 antisense oligonucleotide and $100 \mathrm{ng} / \mathrm{ml}$ cetuximab, $1 \mu \mathrm{g} / \mathrm{ml} \mathrm{5-FU,} 1 \mathrm{ng} / \mathrm{ml}$ paclitaxel or $2 \mathrm{ng} / \mathrm{ml}$ gemcitabine, respectively, demonstrated no significant alteration in the expression pattern of Mcl-1 versus cells treated with $35 \mathrm{nM}$ of the Mcl-1 antisense oligonucleotide alone. Notably, the combination of the antisense oligonucleotide with $1.5 \mu \mathrm{g} / \mathrm{ml}$ cisplatin led to a distinct decrease in Mcl-1 expression in contrast to the antisense oligonucleotide treatment alone (Fig. 2).

A combination of Mcl-1 antisense oligonucleotide treatment with various substances showed different cytotoxic effects in the cell line. SCC9 cells were incubated with $35 \mathrm{nM}$ Mcl-1 antisense oligonucleotide, universal control oligonucleotide or TransFectin alone. After $24 \mathrm{~h}$ of culturing in serum-containing medium, cisplatin $(0.3,0.9,1.5,2.4$ and $3 \mu \mathrm{g} / \mathrm{ml}), 5-\mathrm{FU}(1,5$, $8,10$ and $12 \mu \mathrm{g} / \mathrm{ml})$, gemcitabine $(2,5,10,12$ and $15 \mathrm{ng} / \mathrm{ml})$, paclitaxel $(0.5,1,2,3$ and $5 \mathrm{ng} / \mathrm{ml})$ or cetuximab $(25,50,75$, 100 and $150 \mathrm{ng} / \mathrm{ml}$ ) were added for $24 \mathrm{~h}$ (Fig. 3A-E). Cell proliferation assays were used to determine the number of viable cells after treatment with oligonucleotide and the different agents. Possible synergistic cytotoxic effects of the combined treatments were calculated separately for each drug dose using the formula described by Aapro et al (12).

After the antisense oligonucleotide monotreatment, an $\sim 50-60 \%$ reduction in cell number compared with the untreated controls was observed. In the SCC9 cell line, the Mcl-1 antisense oligonucleotide acted synergistically with paclitaxel, gemcitabine and cetuximab in all of the applied concentrations. Treatment with Mcl-1 antisense oligonucleotide in combination with cisplatin clearly reduced the number of viable cells versus
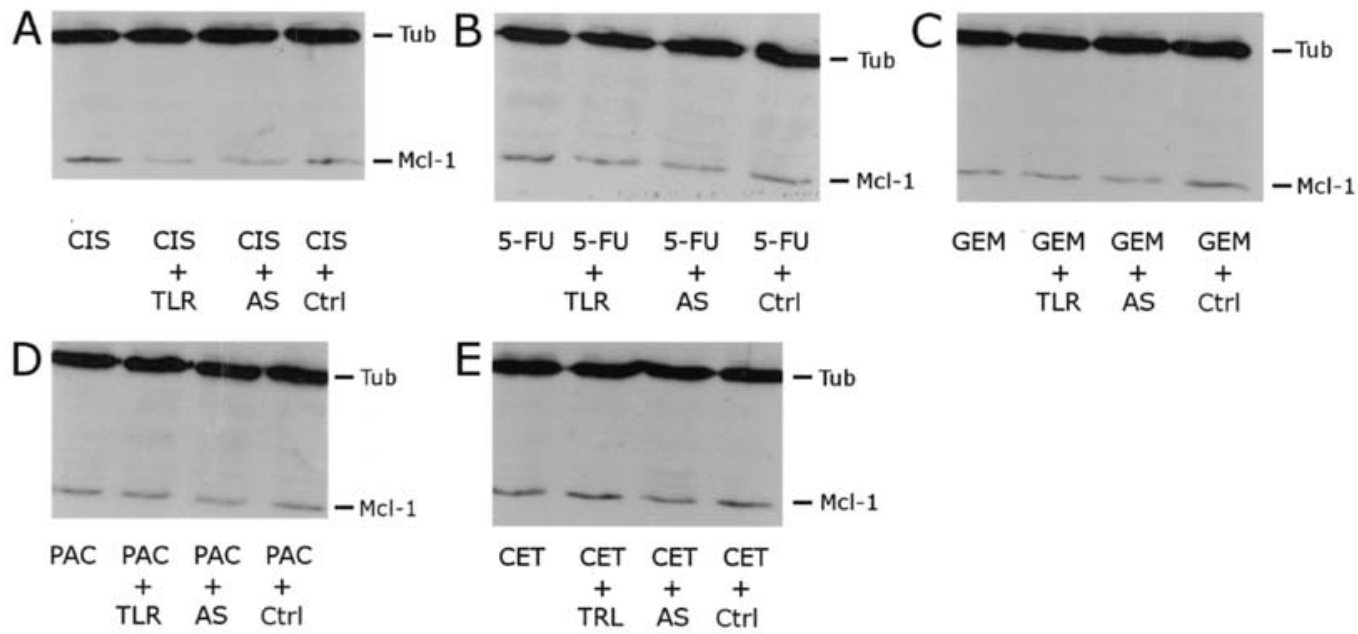

Figure 2. Western blot analysis of Mcl-1 expression in head and neck cancer cells. Mcl-1 antisense oligonucleotide-treated SCC9 cells $24 \mathrm{~h}$ after incubation with (A) $1.5 \mu \mathrm{g} / \mathrm{ml}$ cisplatin (CIS), (B) $1 \mu \mathrm{g} / \mathrm{ml} \mathrm{5-FU} \mathrm{(5-FU),} \mathrm{(C)} 2 \mathrm{ng} / \mathrm{ml}$ gemcitabine (GEM), (D) $1 \mathrm{ng} / \mathrm{ml} \mathrm{paclitaxel} \mathrm{(PAC)} \mathrm{or} \mathrm{(E)} 100 \mathrm{ng} / \mathrm{ml}$ cetuximab (CET). Lane 1, each cytotoxic agent (CIS, 5-FU, GEM, PAC or CET) alone; lane 2, each cytotoxic agent + TransFectin control (TLR); lane 3, each cytotoxic agent + Mcl-1 antisense oligonucleotide (AS), lane 4, each cytotoxic agent + universal control oligonucleotide (Ctrl) 


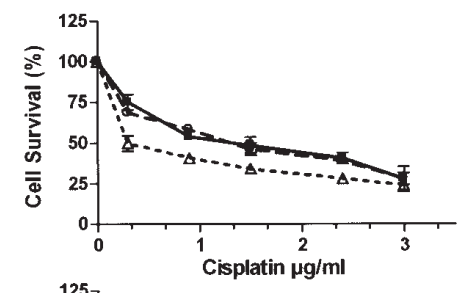

$\rightarrow \mathrm{ClS}$

$-\leadsto-\mathrm{CIS}+\mathrm{AS}$

$\rightarrow$ CIS $+\mathrm{Crtt}$

a


$-\triangle-5-F U+A S$

$\rightarrow \cdot 5-\mathrm{FU}+\mathrm{CrH}$

b

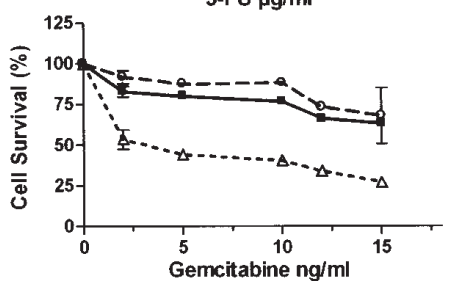

$\rightarrow$ GEM

-Ъ-GEM + AS

$\rightarrow$ GEM + Crt

C

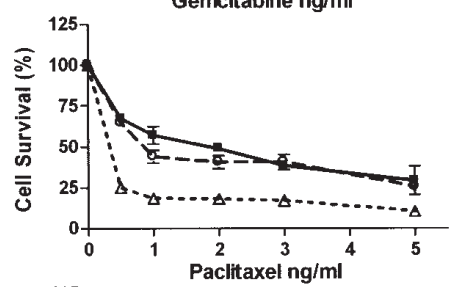

$\rightarrow P A C$

$-\triangle-P A C+A S$

$\leadsto \cdot P A C+C r t$

d

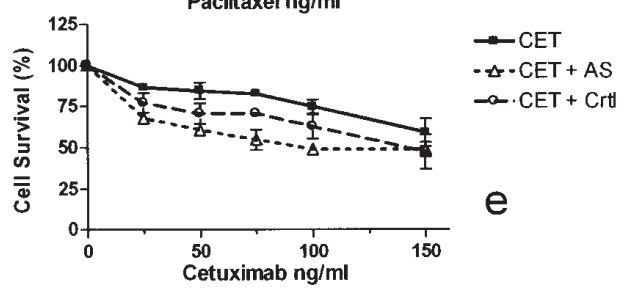

Figure 3. The dose response curves of the SCC9 cell line treated with Mcl-1 antisense oligonucleotide (AS) or universal control oligonucleotide (Ctrl) and/or (a) cisplatin (CIS, a); gemcitabine (GEM, b); 5-FU (5-FU, c); paclitaxel (PAC, d) or cetuximab (CET, e), respectively. Each value represents the mean \pm SEM of three independent experiments.

the control cells treated with cisplatin alone. However, we only observed a moderate synergism at this combination.

Assessment of apoptosis in the SCC9 cell line. To investigate whether the chemosensitizing effect of the Mcl-1 antisense oligonucleotide was linked to a higher number of apoptotic cells, we used the M30 antibody for immunohistochemistry. In the SCC9 cell line, treatment with the Mcl-1 antisense oligonucleotide in combination with cetuximab, gemcitabine and paclitaxel, respectively, led to a distinct increase of apoptotic (red) cells compared with the cells treated with the cytotoxic agent alone (Fig. 4A-F). On the other hand, SCC9 cells showed no significant alteration in the number of apoptotic cells after adding Mcl-1 antisense oligonucleotide to the treatment with 5-FU (data not shown).

\section{Discussion}

We investigated the influence of Mcl-1 expression on the sensitivity of the human squamous cell carcinoma cell line
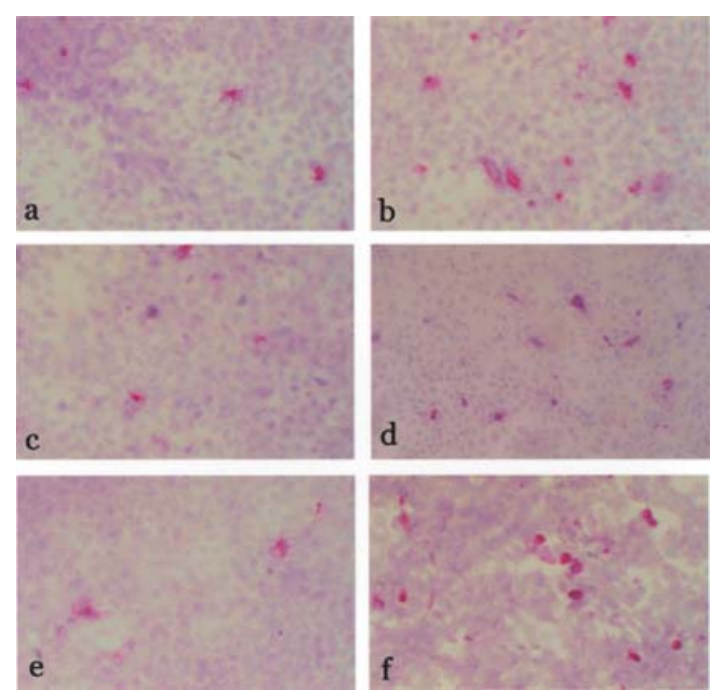

Figure 4. The detection of apoptotic cells using the M30 antibody after treatment with the various cytotoxic agents. The left column represents cells treated with the standard pharmaceuticals of cetuximab (a), gemcitabine (c) and paclitaxel (e). The right column shows cells treated with Mcl-1 antisense (AS) in combination with these drugs: cetuximab + AS (b), gemcitabine + AS (d) and paclitaxel + AS (f). The apoptotic cells stand out due to red staining. All photomicrographs were taken at a magnification of $\mathrm{x} 400$.

SCC9 to the cytotoxic agents cisplatin, 5-FU, gemcitabine, paclitaxel and cetuximab by introducing an antisense oligonucleotide strategy. Antisense oligonucleotides have recently been identified as new anticancer agents (6). Antisense strategies using mono or bispecific antisense oligonucleotides against Bcl-2 (13-15), Bcl-XL $(13,14,16)$ and Mcl-1 $(7,17)$ have shown promising results as new treatment strategies for several human malignancies. In this study, we used an Mcl-1 antisense oligonucleotide previously shown to be able to down-regulate the Mcl-1 expression in endothelial (18) and melanoma cells (17) and in human sarcoma xenotransplants (7).

The effects of a decreased Mcl-1 expression on different cytotoxic treatments in HNSCC cells have yet to be investigated. Therefore, we set up this study to explore whether an Mcl-1 antisense oligonucleotide qualified as a chemosensitizing agent in a human HNSCC cell line. We used five different chemotherapeutic substances, including the DNA-damaging drug cisplatin, which is probably the most widely used chemotherapeutic agent in head and neck cancer. However, the development of cisplatin resistance is a major obstacle in clinical treatment that may be mediated by a number of different mechanisms, including the overexpression of antiapoptotic proteins (19). We also tested the taxan, paclitaxel, which enhances the stabilization of microtubules during cell division (3) and has reported response rates of $\sim 30 \%$ in the treatment of patients with recurrent or metastatic HNSCC (20). Additionally, we studied the effects of the Mcl-1 suppression on the cytotoxicity of the monoclonal antibody cetuximab. Cetuximab, also known as C225, binds to the epidermal growth factor receptor (EGFR), a member of the ErbB family of receptor tyrosine kinases, with a high affinity thereby blocking growth-factor binding (21). EGFR is abnormally activated in epithelial cancers such as head and 
neck cancer $(22,23)$. A multinational, randomized study compared radiotherapy alone with radiotherapy + cetuximab and showed excellent results regarding the median duration of the locoregional control and of the overall survival in the group of patients that received cetuximab. However, this only held true for patients with a squamous cell carcinoma of the oropharynx. In this study, the authors did not observe significant changes in the median duration of the locoregional control and of the overall survival in the patients with cancer of the hypopharynx or larynx (24). This may imply a tissuespecific drug effect of cetuximab.

We demonstrated by Western blot analysis that Mcl-1 is widely expressed in SCC9 cells. Treatment with Mcl-1 antisense oligonucleotide was found to be very efficient, because $24 \mathrm{~h}$ after transfection with the antisense oligonucleotide, we detected a strong reduction in Mcl-1 expression in our cell line. The combination of Mcl-1 antisense oligonucleotide and the different study drugs showed no remarkable alteration in Mcl-1 expression compared with the antisense oligonucleotide treatment alone, except for the combination with cisplatin. The exact mechanisms by which the antisense oligonucleotide works together with cisplatin regarding the Mcl-1 expression levels are unclear at this time.

We performed cell proliferation experiments to determine the number of viable HNSCC cells after treatment with the antisense oligonucleotide alone or in combination with the cytotoxic drugs tested. In the SCC9 cell line, the combined treatment with the Mcl-1 antisense oligonucleotide and paclitaxel, gemcitabine, cetuximab and cisplatin, respectively, in all of the applied doses and partly with 5-FU, resulted in a significant decrease in cell viability. However, the combination with the modern substances such as paclitaxel or cetuximab showed a synergistic cytotoxic effect.

We employed immunohistochemistry to assess the induction of apoptosis. We demonstrated a significant increase of apoptosis after treatment with the Mcl-1 antisense oligonucleotide in combination with paclitaxel, gemcitabine, cetuximab or cisplatin. In contrast, we did not observe an induction of apoptosis after the antisense treatment was combined with 5-FU.

To the best of our knowledge, the direct functional role of Mcl-1 in HNSCC or other epithelial cell lines has yet to be shown. Selzer et al (25) speculated that the overexpression of an antiapoptotic protein such as $\mathrm{Mcl}-1$ by an apoptosisinducing substance may reflect an adaptive response to a cytotoxic stimulus. In our case, it is possible that the SCC9 cell line is protected against the combined effects of the Mcl-1 antisense oligonucleotide and 5-FU by overexpressing Mcl-1.

In summary, we demonstrated that Mcl-1 is effectively down-regulated with the described Mcl-1 antisense oligonucleotide therapy. We also showed that Mcl-1 plays an important role as a chemoresistance factor in our HNSCC cell line. Most importantly, we achieved a synergistic cytotoxic effect when combining Mcl-1 antisense oligonucleotide treatment with modern cytotoxic drugs such as paclitaxel or the immunotherapeutic agent cetuximab.

\section{References}

1. Hasina R and Lingen MW: Head and neck cancer: the pursuit of molecular diagnostic markers. Semin Oncol 31: 718-725, 2004.
2. Posner MR, Haddad RI, Wirth L, et al: Induction chemotherapy in locally advanced squamous cell cancer of the head and neck: evolution of the sequential treatment approach. Semin Oncol 31: 778-785, 2004.

3. Adamo V, Ferraro G, Pergolizzi S, et al: Paclitaxel and cisplatin in patients with recurrent and metastatic head and neck squamous cell carcinoma. Oral Oncol 40: 525-531, 2004.

4. Brockstein B and Vokes EE: Concurrent chemoradiotherapy for head and neck cancer. Semin Oncol 31: 786-793, 2004.

5. Forastiere A, Koch W, Trotti A and Sidransky D: Head and neck cancer. N Engl J Med 345: 1890-1900, 2001.

6. Jansen B and Zangemeister-Wittke U: Antisense therapy for cancer - the time of truth. Lancet Oncol 3: 672-683, 2002.

7. Thallinger C, Wolschek MF, Maierhofer $\mathrm{H}$, et al: Mcl-1 is a novel therapeutic target for human sarcoma: synergistic inhibition of human sarcoma xenotransplants by a combination of mcl-1 antisense oligonucleotides with low-dose cyclophosphamide. Clin Cancer Res 10: 4185-4191, 2004.

8. Keith FJ, Bradbury DA, Zhu YM and Russell NH: Inhibition of bcl-2 with antisense oligonucleotides induces apoptosis and increases the sensitivity of AML blasts to Ara-C. Leukemia 9: 131-138, 1995.

9. Kitada S, Takayama S, De Riel K, Tanaka S and Reed JC: Reversal of chemoresistance of lymphoma cells by antisensemediated reduction of bcl-2 gene expression. Antisense Res Dev 4: 71-79, 1994.

10. Hotz MA, Bosq J, Zbaeren P, et al: Spontaneous apoptosis and the expression of p53 and $\mathrm{Bcl}-2$ family proteins in locally advanced head and neck cancer. Arch Otolaryngol Head Neck Surg 125: 417-422, 1999.

11. Fujise K, Zhang D, Liu J and Yeh ET: Regulation of apoptosis and cell cycle progression by MCL1. Differential role of proliferating cell nuclear antigen. J Biol Chem 275: 39458-39465, 2000.

12. Aapro MS, Alberts DS and Salmon SE: Interactions of human leukocyte interferon with vinca alkaloids and other chemotherapeutic agents against human tumors in clonogenic assay. Cancer Chemother Pharmacol 10: 161-166, 1983.

13. Olie RA, Hafner C, Kuttel R, et al: Bcl-2 and bcl-xL antisense oligonucleotides induce apoptosis in melanoma cells of different clinical stages. J Invest Dermatol 118: 505-512, 2002.

14. Sharma H, Sen S, Lo Muzio L, Mariggio A and Singh N: Antisense-mediated down-regulation of anti-apoptotic proteins induces apoptosis and sensitizes head and neck squamous cell carcinoma cells to chemotherapy. Cancer Biol Ther 4: 720-727, 2005.

15. Wacheck V, Heere-Ress E, Halaschek-Wiener J, et al: Bcl-2 antisense oligonucleotides chemosensitize human gastric cancer in a SCID mouse xenotransplantation model. J Mol Med 79: 587-593, 2001.

16. Heere-Ress E, Thallinger C, Lucas T, et al: Bcl-X(L) is a chemoresistance factor in human melanoma cells that can be inhibited by antisense therapy. Int J Cancer 99: 29-34, 2002.

17. Thallinger C, Wolschek MF, Wacheck V, et al: Mcl-1 antisense therapy chemosensitizes human melanoma in a SCID mouse xenotransplantation model. J Invest Dermatol 120: 1081-1086, 2003.

18. Bannerman DD, Tupper JC, Ricketts WA, Bennett CF, Winn RK and Harlan JM: A constitutive cytoprotective pathway protects endothelial cells from lipopolysaccharide-induced apoptosis. J Biol Chem 276: 14924-14932, 2001.

19. Lee SK, Kim SB, Kim JS, et al: Butyrate response factor 1 enhances cisplatin sensitivity in human head and neck squamous cell carcinoma cell lines. Int J Cancer 117: 32-40, 2005.

20. Forastiere AA: Use of paclitaxel (Taxol) in squamous cell carcinoma of the head and neck. Semin Oncol 20: 56-60, 1993.

21. Baselga J: The EGFR as a target for anticancer therapy - focus on cetuximab. Eur J Cancer 37: S16-S22, 2001.

22. Hynes NE and Lane HA: ERBB receptors and cancer: the complexity of targeted inhibitors. Nat Rev Cancer 5: 341-354, 2005.

23. Mendelsohn J and Baselga J: Status of epidermal growth factor receptor antagonists in the biology and treatment of cancer. J Clin Oncol 21: 2787-2799, 2003.

24. Bonner JA, Harari PM, Giralt J, et al: Radiotherapy plus cetuximab for squamous-cell carcinoma of the head and neck. $\mathrm{N}$ Engl J Med 354: 567-578, 2006.

25. Selzer E, Pimentel E, Wacheck V, et al: Effects of betulinic acid alone and in combination with irradiation in human melanoma cells. J Invest Dermatol 114: 935-940, 2000. 